\title{
Integration of temporal environmental variation by the marine plankton community
}

\author{
Andrew D. Barton ${ }^{1, *}$, Fernando González Taboada ${ }^{2,3}$, Angus Atkinson ${ }^{4}$, \\ Claire E. Widdicombe ${ }^{4}$, Charles A. Stock ${ }^{3}$
}

\begin{abstract}
${ }^{1}$ Scripps Institution of Oceanography and Section of Ecology, Behavior and Evolution, University of California San Diego, La Jolla, CA 92037, USA

${ }^{2}$ Atmospheric and Oceanic Sciences Program, Princeton University, Princeton, NJ 08540, USA

${ }^{3}$ Geophysical Fluid Dynamics Laboratory, National Oceanic and Atmospheric Administration, Princeton, NJ 08540, USA

${ }^{4}$ Plymouth Marine Laboratory, Plymouth PL1 3DH, UK
\end{abstract}

\begin{abstract}
Theory and observations suggest that low frequency variation in marine plankton populations, or red noise, may arise through cumulative integration of white noise atmospheric forcing by the ocean and its amplification within food webs. Here, we revisit evidence for the integration of stochastic atmospheric variations by comparing the power spectra of time series of atmospheric and oceanographic conditions to the population dynamics of 150 plankton taxa at Station L4 in the Western English Channel. The power spectra of oceanographic conditions (sea surface temperature, surface nitrate) are redder than those of atmospheric forcing (surface wind stress, net heat fluxes) at Station L4. However, plankton populations have power spectral slopes across trophic levels and body sizes that are redder than atmospheric forcing but whiter than oceanographic conditions. While zooplankton have redder spectral slopes than phytoplankton, there is no significant relationship between power spectral slope and body size or generation length. Using a predator-prey model, we show that the whitening of plankton time series relative to oceanographic conditions arises from noisy plankton bloom dynamics in this strongly seasonal system. The model indicates that, for typical predator-prey interactions, where the predator is on average 10 times longer than the prey, grazing leads to a modest reddening of phytoplankton variability by their larger and longer lived zooplankton consumers. Our findings suggest that, beyond extrinsic forcing by the environment, predator-prey interactions play a role in influencing the power spectra of time series of plankton populations.
\end{abstract}

${ }^{*}$ Corresponding author: adbarton@ucsd.edu

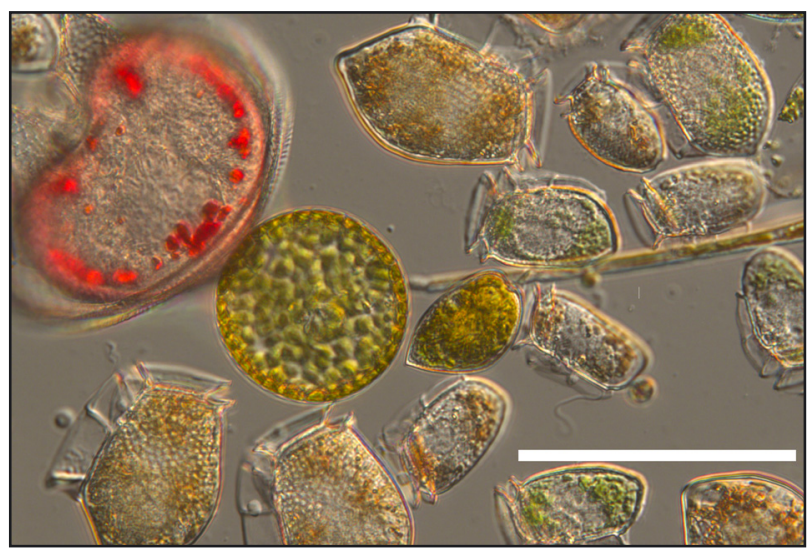

Observations of the plankton community at Station L4 in the Western English Channel illustrate how environmental change influences variability in plankton populations across trophic levels. Scale bar $=100 \mu \mathrm{m}$

Photo: Claire Widdicombe, Plymouth Marine Laboratory

KEY WORDS: Phytoplankton · Zooplankton · Climate · Station L4 $\cdot$ Population dynamics

\section{INTRODUCTION}

In the marine environment, plankton populations exhibit considerable variability on a broad range of timescales, from rapid diel changes in cell size (Hunter-Cevera et al. 2014) or position in the water column (Lampert 1989) to much longer term and lower frequency interannual- (Behrenfeld et al. 2006),

(1) The authors 2020. Open Access under Creative Commons by Attribution Licence. Use, distribution and reproduction are unrestricted. Authors and original publication must be credited. 
decadal- (Fromentin \& Planque 1996, Edwards et al. 2013), and centennial-scale fluctuations (Barton et al. 2016). These longer term and lower frequency variations in plankton populations present a particular challenge to marine scientists and resource managers. Not only can they impact biogeochemical cycles, marine food webs, and fisheries on human-relevant timescales (Hare \& Mantua 2000, Henson et al. 2012), but their causes, links to climate variability, and consequences often remain poorly understood.

Low frequency variability in plankton populations and communities can arise from a range of abiotic and biotic mechanisms (Steele 1985). For example, climate variability patterns such as the El NiñoSouthern Oscillation, the Atlantic Multidecadal Oscillation, and the Pacific Decadal Oscillation are associated with low frequency, persistent, and lasting changes in environmental conditions. Variations in temperature or upwelling and nutrient supply consequently impact plankton biomass, phenology, and community structure (Fromentin \& Planque 1996, Hare \& Mantua 2000, Behrenfeld et al. 2006, Di Lorenzo \& Ohman 2013, Edwards et al. 2013). The marine environment in particular is prone to longperiod oscillations of this type (Steele 1985, Vasseur \& Yodzis 2004). Anthropogenic climate change will continue to alter ocean environments in the coming century (Bopp et al. 2013), providing an additional long-term agent of change in marine plankton communities (Edwards \& Richardson 2004, Dutkiewicz et al. 2015, Barton et al. 2016).

Low frequency variations may also arise from biological mechanisms, independent from or synergistically with environmental forcing. Even simple monoculture experiments with constant environmental conditions can exhibit population variability through time (Nicholson 1957), and coupled predator-prey dynamics may exhibit low frequency variations (Gause et al. 1936). Nonlinear and lagged effects are common in marine species exhibiting complex life cycles or subject to tight predation control or exploitation (Roughgarden 1988, Hsieh et al. 2005, Anderson et al. 2008). In cases where organism generation time matches the dominant timescales of environmental forcing, complex and low frequency population dynamics are possible (Hsieh \& Ohman 2006). These fluctuations may exert long-lasting effects on population dynamics, inducing regime-shift-like behavior (Hare \& Mantua 2000, Rudnick \& Davis 2003, Overland et al. 2006).

Low frequency variability may also arise by species or communities filtering environmental noise. In this context, filtering implies that population dynamics differ from that of the underlying environmental variability. Considerable theoretical work on this topic has explored the consequences of environmental noise on population variability, extinction, and persistence (e.g. Royama 1981, Ruokolainen et al. 2009, GarcíaCarreras \& Reuman 2011, Ferguson et al. 2016), generally by considering single-species dynamics and models. Studies focusing on the propagation of environmental variability through entire ecosystems or food webs are fewer (e.g. Xu \& Li 2002, Ripa \& Ives 2003, Vasseur \& Fox 2007, Di Lorenzo \& Ohman 2013), but have highlighted that the sensitivity of individual taxa in the food web depends upon food web structure (Xu \& Li 2002). Multi-species studies have also highlighted how synchrony in the response of interacting species determines patterns of population variability and coexistence (Ripa \& Ives 2003, Vasseur \& Fox 2007). Using data from a few indicator species, Di Lorenzo \& Ohman (2013) hypothesized that stochastic environmental forcing, when filtered over 2 plankton trophic levels, could generate pronounced low frequency variation in zooplankton populations.

The contrasting behaviors of environment variables and biological populations can be summarized through spectral analysis (Platt \& Denman 1975, Inchausti \& Halley 2001, Vasseur \& Yodzis 2004). Power spectral analysis quantifies the amount of variance in a time series occurring at each of a range of frequencies, and the power spectral slope describes the relative amount of variance at each frequency. A population with equal variance at all frequencies has a power spectral slope close to zero and is said to exhibit 'white' noise. When variance is concentrated in lower compared with higher frequencies, the power spectral slope is negative and the population is said to exhibit 'red' noise.

Here, we characterized the spectral properties of environmental conditions and population time series for 150 phytoplankton, microzooplankton (operationally defined as zooplankton passing through a $200 \mu \mathrm{m}$ filter), and mesozooplankton taxa (zooplankton larger than $200 \mu \mathrm{m})$. The data come from the long-term research and monitoring program at Station L4 in the Western English Channel, located $13 \mathrm{~km}$ southwest of Plymouth, UK $\left(50^{\circ} 15.00^{\prime} \mathrm{N}\right.$, $4^{\circ} 13.02^{\prime} \mathrm{W}$ ) in a water depth of ca. $55 \mathrm{~m}$. The program provides an intensive, high-resolution plankton time series with roughly weekly sampling of zooplankton since 1988 and phytoplankton and microzooplankton since 1992. The organisms studied span over 8 orders of magnitude in body mass (Table S1 in the Supplement at www.int-res.com/articles/suppl/ 
m647p001_supp.pdf) and multiple trophic levels. We also used time series of key co-located environmental data, including sea surface temperature (SST), sea surface nitrate, net air-sea heat fluxes, and surface wind stress, to quantify spectral properties of the environment and compare these metrics across plankton taxa and between environmental drivers. Specifically, we asked: (1) What is the color of noise for the key environmental variables thought to influence plankton communities; (2) How does the environmental noise compare with spectral properties of observed plankton; and (3) How does the color of noise vary across plankton body size and trophic levels?

To further interpret empirical results from Station L4, we developed and parameterized a simple predator-prey model of the plankton community within realistic ranges of body size and associated functional traits (the model is described in Section 2.4). The model allowed us to assess the response of population variability to forced environmental conditions mimicking observed fluctuations in light and nutrient availability/concentration at Station L4. In addition, we discuss our empirical and modeling results in the context of the 'double-integration model' (Di Lorenzo \& Ohman 2013), a popular conceptual framework and set of hypotheses to explain how low frequency variations in zooplankton populations may arise through cumulative integrations of noisy atmospheric forcing. We describe the double-integration model and the testable hypotheses it poses in Section 2.5.

\section{MATERIALS AND METHODS}

\subsection{Station L4 plankton data}

Plankton time series data were collected from Station L4 on a weekly basis, weather-permitting. Phytoplankton and microzooplankton were enumerated using water samples collected at a depth of $10 \mathrm{~m}$, using a 101 Niskin bottle (Widdicombe et al. 2010a). Paired $200 \mathrm{ml}$ sub-samples were immediately preserved with acid-Lugol's iodine for the enumeration of diatoms, dinoflagellates, ciliates, and flagellates and neutral formaldehyde for the enumeration of coccolithophores (Widdicombe et al. 2010b). Samples were subsequently analyzed at Plymouth Marine Laboratory using settlement light microscopy (Utermöhl 1958). Mesozooplankton were collected using replicate $0-50 \mathrm{~m}$ vertical WP2 net hauls $(200 \mu \mathrm{m}$ mesh net, $0.57 \mathrm{~cm}$ diameter mouth) and immediately preserved in neutral formaldehyde (McEvoy et al. 2012, Atkinson et al. 2019). Taxonomic composition and abun- dance were determined on a series of aliquots from each net haul (depending on abundance) and analyzed using light microscopy (Eloire et al. 2010).

We examined the phytoplankton, microzooplankton, and mesozooplankton abundance time series assembled from observations at Station L4 for 1996-2014, 1996-2014, and 1988-2014, respectively. We converted abundance, $P_{t}$ (units of cells $\mathrm{l}^{-1}$ for phytoplankton and microzooplankton; number $\mathrm{m}^{-3}$ for mesozooplankton) to natural log-transformed values, $\ln \left(P_{t}+1\right)$. Multiple weeks during a month were typically sampled, so we calculated the monthly mean from the available, log-transformed data. In the very few cases $(<1 \%$ of months) where no sampling was done during a month, missing data were linearly interpolated between adjacent months. Monthly anomaly time series were obtained by first calculating the climatological seasonal cycle of log-transformed abundance, and then subtracting the climatology from the log-transformed abundance time series. The monthly climatology was calculated by averaging all available months across the time series (e.g. the climatology for January is the average of all January data from 1996-2014 for phytoplankton). The anomaly time series were then detrended by subtracting a nonparametric linear Theil-Sen trend (Theil 1950). Only time series with significant linear trends $(\mathrm{p}<0.05)$ were detrended; 51,89 , and $65 \%$ of phytoplankton, microzooplankton, and mesozooplankton time series, respectively, had significant trends that were removed. Most, but not all, of the taxa considered in this study have generation times shorter than the standardized monthly time series. Though monthly averaging is desirable, it may also remove higher frequency variability. By removing the pronounced seasonal cycle and long-term trends (which other studies have considered in depth; e.g. Widdicombe et al. 2010b), we focused our analysis on variability occurring at residual timescales and their potential causes.

We considered for further analysis only the subset of taxa that have been identified consistently over the duration of sampling at Station L4, and those taxa that were present in greater than $25 \%$ of monthly samples. The second criteria removed rare and possibly misidentified taxa, and focused the analysis on taxa for which confidence in patterns of abundance was highest; 75,38 , and 37 phytoplankton, microzooplankton, and mesozooplankton taxa, respectively, met these criteria (see Table S1). In addition to sampling at the species level, some of the taxa recorded at Station L4 were identified only to genus level (e.g. Gyrodinium, Strombodinium, Oithona), or grouped ac- 
cording to life history stage (e.g. copepod nauplii, total medusae) or size class (e.g. small pennate diatoms).

There are several aspects of sample collection that may introduce uncertainty into the time series that warrant discussion here. The first is how representative a monthly average value is of that month due to patchiness and higher frequency temporal variability. In other words, did the sampling catch important events, such as blooms, that may have restricted size and duration in the month? The second is how representative a small-volume Lugol's (for phytoplankton) or a pair of WP2 net samples (for zooplankton) is of the wider population at any of the weekly time points, due to patchiness or local scale variability. The third is how representative a counted subsample of that volume is of the actual water volume that was sampled on a particular day. These uncertainties are likely different for each taxon according to its actual patchiness and its rarity, which will determine how many are actually counted and what fraction of the sample is enumerated. Averaging over monthly timescales and eliminating very rare taxa tends to minimize the signature of these types of uncertainty in the monthly time series used in our analyses.

We developed estimates of body size and generation length for each taxon. For each phytoplankton and microzooplankton taxon considered, estimates of cell biovolume were made using mean cell dimensions and appropriate geometric shapes (Kovala \& Larrance 1966) and converted to biomass (pg C cell ${ }^{-1}$ ) according to the equations of Menden-Deuer \& Lessard (2000). To determine mesozooplankton biomass, we generated length-frequency distributions for the dominant taxa for spring (March-May), summer (June-August), autumn (September-November), and winter (December-February). In total, the characteristic lengths (e.g. medusa bell height and diameter and copepod prosome length) of 3780 individuals were measured. From these data we used length-carbon mass relationships from the literature to estimate carbon masses per individual. Over 8 orders of magnitude in carbon body mass were covered by the sampled taxa considered. Though cell or body size can vary considerably over the life history of individuals and in populations through time, for simplicity we used fixed, seasonally averaged values for each taxon (Table S1). We elected to use biomass instead of biovolume in presenting our empirical results because reliable estimates of biovolume are difficult to obtain for the diverse range of zooplankton morphologies present at Station L4. In addition, carbon biomass provides a better representation of metabolically active tissue than does biovolume. For example, gelatinous zoo- plankton are prominent at Station L4, but most of their volume is water (Acuña et al. 2011).

We estimated the generation time of phytoplankton and microzooplankton as the average doubling time $\tau=\ln 2 / \mu$ (in days), where the maximum specific growth rate $\mu\left(\mathrm{d}^{-1}\right)$ was estimated from cell volume (Edwards et al. 2012) and annual mean SST at Station L4 $\left(12.4^{\circ} \mathrm{C}\right)$ using temperature-growth rate relationships (Bissinger et al. 2008). For mesozooplankton generation time, we use published allometric relationships for marine and freshwater rotifers, copepods, and Cladocera (Gillooly 2000), and again assumed an annual mean temperature of $12.4^{\circ} \mathrm{C}$. Estimated generation lengths ranged from less than $1 \mathrm{~d}$ for small phytoplankton to months for larger mesozooplankton.

\subsection{Oceanographic and atmospheric data}

SST and nitrate have strong mechanistic links to plankton physiology and community dynamics (Eppley 1972, Ward et al. 2012). Air-sea heat fluxes and surface wind stress play key roles not only in setting SST and nitrate, but also other chemical and physical properties important to plankton (Barton et al. 2015). We calculated monthly anomaly time series for Station L4 surface nitrate (mmol $\mathrm{N} \mathrm{m}^{-3}$ ) and $\mathrm{SST}\left({ }^{\circ} \mathrm{C}\right)$ over the periods 2000-2014 and 1988-2014, respectively (Smyth et al. 2011, Woodward et al. 2011). Replicate surface measurements of nutrients have been taken on a weekly basis since 2000, and after 2004, analyses were conducted on fresh (rather than frozen) samples using recognized analytical procedures (Woodward \& Rees 2001). Surface temperatures were initially measured using a mercury thermometer in a bucket of freshly collected surface seawater (1988-1998) and then using a CTD system. As such, the error is estimated as \pm 0.1 and $\pm 0.001^{\circ} \mathrm{C}$ for the thermometer and CTD, respectively (Smyth et al. 2010). As with plankton abundance data, environmental data from Station L4 were collected on a roughly weekly basis and were averaged over the month, but without the log transformation. We calculated net heat flux $\left(\mathrm{W} \mathrm{m}^{-2}\right)$ and wind stress $\left(\mathrm{N} \mathrm{m}^{-2}\right)$ time series data from the National Centers for Environmental Prediction and National Center for Atmospheric Research reanalysis monthly mean data for 1948-2012 (Kalnay et al. 1996), using the nearest available ocean grid cell. Net heat flux is the sum of latent, sensible, longwave, and shortwave heat fluxes, and wind stress magnitude is $\left(\tau_{x}^{2}+\tau_{y}^{2}\right)^{\frac{1}{2}}$, where $\tau_{x}$ and $\tau_{y}$ are the zonal and meridional wind stress 
components, respectively. As with the plankton time series, monthly anomalies were calculated by subtracting the corresponding climatological monthly values, and the resulting monthly anomaly time series were detrended by subtracting only significant linear trends $(\mathrm{p}<0.05)$, as calculated by the TheilSen method. We focused on nitrate in this study because it is generally, though not always, a limiting macronutrient in the North Atlantic (Moore et al. 2013). There are, of course, other environmental drivers of importance to plankton (e.g. turbulence; Margalef 1978), but we focused on these key, ecologically meaningful ocean and atmosphere variables that capture the character of variability in the system.

\subsection{Calculating power spectral slopes}

For each time series of interest, we calculated the power spectral density by squaring the amplitude of Fourier coefficients calculated from a fast Fourier transform. The power spectral slope is the linear relationship between the $\log _{10}$-transformed frequency and power at each frequency. To calculate the power spectral slope, we first calculated the median log-transformed power in evenly spaced logarithmic frequency bins. We calculated the slope from this smoother power spectrum using the Theil-Sen method, which is relatively robust to outlying points. In all cases we used anomaly time series (after subtracting the seasonal cycle) to calculate the power spectral density and slope. Using log-transformed abundance data as we have is desirable for calculating power spectral density and the fast Fourier transform because the non-log-transformed anomalies are not normally distributed (Platt \& Denman 1975). Other studies quantifying power spectra of many different populations have also log transformed their abundance data first (Inchausti \& Halley 2003).

\subsection{A simple model of plankton dynamics}

\subsubsection{Predator-prey model formulation}

To help interpret the empirical analyses, we employed an idealized predator-prey plankton model where the power spectra of phytoplankton and zooplankton emerge from prescribed environmental forcing and from well-established allometric relationships for plankton functional traits. The model examines the relationship between a single phytoplankton $(P)$ type with logistic growth subject to a fluctuating carrying capacity $(K)$ and grazed upon by zooplankton $(Z)$, with plankton traits chosen to reflect the range of phytoplankton and zooplankton taxa observed at Station L4:

$$
\begin{gathered}
\frac{\mathrm{d} P}{\mathrm{~d} t}=r P\left(1-\frac{P}{K}\right)-g Z P \\
\frac{\mathrm{d} Z}{\mathrm{~d} t}=\gamma g Z P-m_{Z} Z^{2}
\end{gathered}
$$

Phytoplankton growth is a function of growth rate $\left(r_{i} \mathrm{~d}^{-1}\right)$ and $K\left(\mathrm{mmol} \mathrm{N} \mathrm{m}{ }^{-3}\right) . K, P$, and $Z$ are tracked in nitrogen units $\left(\mathrm{mmol} \mathrm{N} \mathrm{m}^{-3}\right)$. For simplicity, we assume the growth rate $r$ is equivalent to the maximum specific growth rate, $\mu$. Phytoplankton losses to grazing are an increasing linear function of prey density (Holling Type $\mathrm{I})$, and $g\left(\mathrm{~m}^{3}(\mathrm{mmol} \mathrm{N} \mathrm{d})^{-1}\right)$ is the zooplankton clearance rate of phytoplankton. Values of $r$ and $g$ have been found to decrease with increasing body size, and were chosen in each model experiment based upon the allometric relationships reported by Edwards et al. (2012) and Hansen et al. (1997), respectively. In the case of $r$, $\log _{10} r=0.70-0.24 \log _{10} V$, where $V$ is cell volume $\left(\mu \mathrm{m}^{3}\right) . g$ is the ratio of the maximum specific prey ingestion rate $\left(I_{\text {max }} ; \mathrm{d}^{-1}\right)$ divided by a constant grazing half-saturation prey concentration $\left(k_{Z ;}\right.$ set to 3.0 mmol $\mathrm{N} \mathrm{m}^{-3}$ ): $g=I_{\max } / k_{Z}$ (Hansen et al. 1997), where $\log _{10} I_{\max }=-0.04-0.16 \log _{10} V$ (in this case, $V$ is zooplankton body volume, $\mu^{3}$ ). The gross growth efficiency $(\gamma)$ was set to a typical value of 0.3 (Straile 1997). Zooplankton mortality was assumed to be density-dependent (Ohman \& Hirche 2001), with the quadratic form implying that the biomass of unresolved higher trophic level predators scales in proportion with the zooplankton prey. The zooplankton mortality rate $\left(m_{Z} ; \mathrm{m}^{3}(\mathrm{mmol} \mathrm{N} \mathrm{d})^{-1}\right)$ decreases with body size, and was set to be consistent with the allometric relationship reported by McGurk (1986). McGurk reported that mortality rate $\left(M ; \mathrm{d}^{-1}\right)$ is $M=$ $0.00526 D W^{-0.25}$, where $D W$ is zooplankton dry weight $(\mathrm{g})$. We converted $D W$ to zooplankton biovolume $\left(\mu \mathrm{m}^{3}\right)$ using the conversion factors in Hansen et al. (1997), $0.45 \mathrm{~g} \mathrm{C} \mathrm{g}^{-1} \mathrm{DW}$ and $0.12 \mathrm{~g} \mathrm{C} \mathrm{cm}^{-3}$, and scaled $M$ to $m_{Z}$ by dividing by an average zooplankton concentration of $0.5 \mathrm{mmol} \mathrm{N} \mathrm{m}^{-3}$. Though idealized, the model captures essential elements of plankton physiology and interactions. Similar model formulations have been used in previous studies to examine plankton population dynamics (Scheffer et al. 1997, Vasseur 2007, Benincà et al. 2011, Montagnes \& Fenton 2012). In the model, zooplankton includes both microzooplankton and mesozooplankton that are differentiated by size and associated traits. 


\subsubsection{Description of model $K$}

We modeled the ecological effects of environmental variability by prescribing carrying capacity $(K)$. We preferred this idealized model approach to an explicit physiological model representing biological effects of variations in light, nutrients, and temperature (e.g. Stock et al. 2014, Dutkiewicz et al. 2015) because it enabled us to (1) carefully manipulate and control the color of environmental noise and (2) track the responses of populations to environmental noise of a known color. Previous modeling studies investigating the filtering of environmental noise by ecosystems have also used $K$ in a similar manner (Vasseur 2007, Ruokolainen \& Ripa 2012).

$K$ in the model is designed to produce plausible seasonal cycles of plankton biomass, in addition to prescribed noise occurring on a full range of timescales. Observed plankton productivity at Station L4 (e.g. Eloire et al. 2010, Smyth et al. 2010, Widdicombe et al. 2010b) exhibits 2 dominant properties that are influenced to a great degree by light and nutrient availability: (1) productive spring to fall periods interrupted by low light and low productivity winters; (2) productivity during the high-light growing season is strongly shaped by mixing of water column in spring, fall, and winter months and subsequent nutrient resupply from depth in winter. Thus, light shapes the overall seasonality of $K$-low in the winter and high in the summer - and the availability of nutrients sets the seasonal amplitude and magnitude of noise in $K$. To capture the essence of these characteristics in a conceptually simple and tractable way, we let the model $K$ time series be composed of a repeating climatological seasonal cycle $\left(\mathcal{N}_{S}\right)$ with noise of a known spectral color $\left(\alpha \mathcal{N}_{t}\right)$ added:

$$
K=\left(\mathcal{N}_{s}+\alpha \mathcal{N}_{t}\right)^{2}
$$

We linked the timing and shape of $\mathcal{N}_{S}$ to the seasonal cycle of light at Station L4, but scaled the magnitude of $\mathcal{N}_{S}$ to nitrate. In other words, $K$ increases in spring, is highest in summer, decreases in the fall, and is lowest in the winter (Fig. S1). To obtain $\mathcal{N}_{s}$, we first calculated the climatological seasonal cycle of photosynthetically active radiation (PAR) using satellite-derived monthly averaged MODIS-Aqua data from 2002-2017 at Station L4 (NASA OBPG 2017). The climatological seasonal cycle of PAR was then interpolated onto the model time step ( $2 \mathrm{~h})$ using a periodic spline such that year-end and year-start values of PAR were identical. Second, we normalized the climatological seasonal cycle of $\mathrm{PAR}\left(\mathrm{PAR}_{\mathrm{t}}\right.$, with unitless values ranging from 0-1), and then scaled the normalized PAR data by the dynamic range in the square root of nitrate: $\mathcal{N}_{s}=\mathrm{PAR}_{\mathrm{t}}\left(N_{\max }-N_{\min }\right)+N_{\min }$, where $N_{\max }$ and $N_{\text {min }}$ are the square roots of maximum and minimum climatological monthly concentrations of nitrate at Station L4, respectively (nutrient data are described above in Section 2.2).

$\mathcal{N}_{t}$ is a red-noise process simulated using the spectral superposition method of Timmer and König (1995). We explored noise colors ranging from 0 (white noise) to -1.5 (red noise), covering a range typically seen in the marine environment (Vasseur \& Yodzis 2004). $\alpha$ is a scale factor intended to match the variance of the noise to the observed variance of nitrate anomalies at Station L4. $\mathcal{N}_{s}+\alpha \mathcal{N}_{t}$ is squared to convert back into units of $\mathrm{mmol} \mathrm{N} \mathrm{m}^{-3}$. Observed nutrients and simulated $K$ therefore have very similar spectral characteristics and appearance.

The power spectral slope of $K$ roughly matches the color of the noise added in $\alpha \mathcal{N}_{t}$, after the seasonal cycle has been removed. This simplification of linking $K$ to light and nitrate allowed us to force the model in an idealized manner with a $K$ of a known spectral color and diagnose the resulting ecological dynamics. We did not implement the model in a spatially explicit context, instead opting for the simplicity of a plausible local $K$, but acknowledge the plankton community and environment at Station L4 are an open system impacted by horizontal and vertical transport.

\subsubsection{Model experiments}

We implemented the idealized model in 3 separate experiments. In the first experiment, we used a fixed $K$ with a power spectral slope of approximately -1.0 to assess how the power spectra of one pair of phytoplankton and zooplankton respond to known environmental variations. In this case, predator and prey body sizes are separated in equivalent spherical diameter (ESD) by a factor of 10, an average value observed across multiple types of zooplankton (Hansen et al. 1994). The nominal size of the predator and prey are 100 and $10 \mu \mathrm{m}$ in ESD, respectively. In the second experiment, we used the same pair of phytoplankton and zooplankton, but varied the character of $K$ (described in Section 2.4.2) to assess how the power spectra of phytoplankton and zooplankton respond to a range of known environmental variations. In this case, the power spectral slope of $K$ varied from 0 to -1.5. In the third experiment, we instead fixed the $K$ power spectral slope back to -1.0 , and then examined how different pairs of phytoplankton and zooplankton 
respond to this forcing. Specifically, we simulated pairs of phytoplankton and zooplankton ranging from 5-200 and 50-2000 $\mu \mathrm{m}$ ESD, respectively, though in all cases the pairs of predator and prey had a body size ratio of 10:1. For example, we considered prey and predator pairs of 5 and $50 \mu \mathrm{m}, 25$ and $250 \mu \mathrm{m}$, etc. These size ranges for phytoplankton and zooplankton roughly correspond with the dominant sizes of predators and prey at Station L4.

\subsection{Theoretical framework: the double-integration model}

Di Lorenzo \& Ohman (2013) proposed a doubleintegration model to explain the contrasting population dynamics observed in 2 species of krill in the California Current Ecosystem: Nyctiphanes simplex and Euphausia pacifica. Abundance time series for both species exhibited red power spectra, with $N$. simplex being the redder (more negative) of the two. They argued that red noise variation in $N$. simplex arises from a double integration of noisy atmospheric forcing: the atmosphere first impacts ocean currents and surface conditions before secondarily generating much lower frequency variability in zooplankton populations.

In the model, the temporal evolution of an ocean surface variable $\phi(t)$ - SST for example (Frankignoul \& Hasselmann 1977, Hall \& Manabe 1997, Deser et al. 2010) — can be described as a first-order autoregressive process (AR-1; Ives et al. 2010):

$$
\frac{\mathrm{d} \phi(t)}{\mathrm{d} t}=f(t)-\frac{\phi(t)}{\tau_{\phi}}
$$

where $f(t)$ is white noise forcing by the atmosphere and $\tau_{\phi}$ is the decorrelation timescale associated with the ocean surface variable. For $\tau_{\phi}=6 \mathrm{mo}$, a value typical of SST (Frankignoul \& Hasselmann 1977), the time series of $\phi(t)$ is smoother than $f(t)$, and the negative log-log slope of the power spectra for $\phi(t)$ indicates that $\phi(t)$ has more power in low than high frequencies (i.e. red noise; Fig. 1a,b).

In the second AR-1 integration, changes in the natural logarithm of
$N$. simplex abundance $(Z(t))$ depends both on SST forcing and on $Z(t)$ :

$$
\frac{\mathrm{d} Z(t)}{\mathrm{d} t}=\phi(t)-\frac{Z(t)}{\tau_{Z}}
$$

where $\tau_{z}$ is the $N$. simplex generation length. Di Lorenzo \& Ohman (2013) set $\tau_{Z}=24 \mathrm{mo}$, though $\tau_{Z}$ generally increases with body size and is shorter for most zooplankton taxa (Gillooly 2000, Hirst \& Bunker 2003). The resulting zooplankton anomaly time series $(Z(t))$ is even smoother than SST $(\phi(t))$, and has a much redder power spectral slope (Fig. 1c).

In contrast to N. simplex, E. pacifica exhibited considerable interannual variability that may arise from a single, rather than double, integration of atmospheric forcing. In this case, changes in Ekman currents, upwelling, and phytoplankton abundance closely track noisy changes in coastal winds. E. pacifica integrate over this noisy forcing and consequently have smoother and redder population dynamics. E. paci-
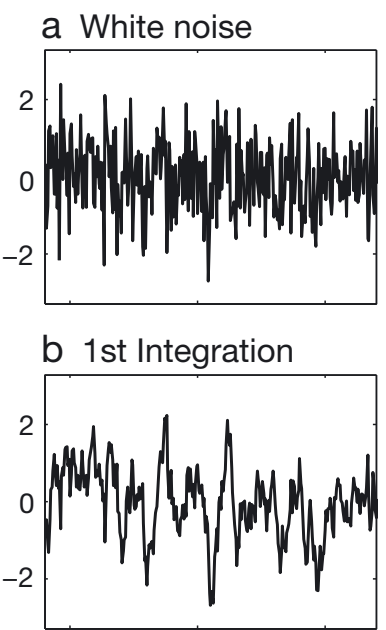

c 2nd Integration

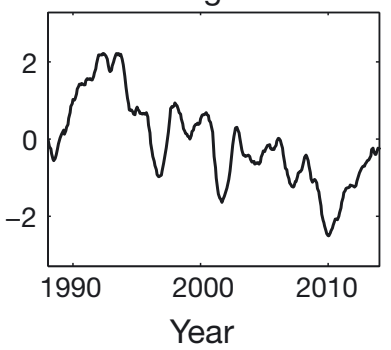

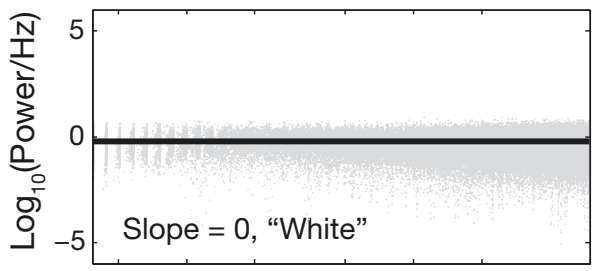
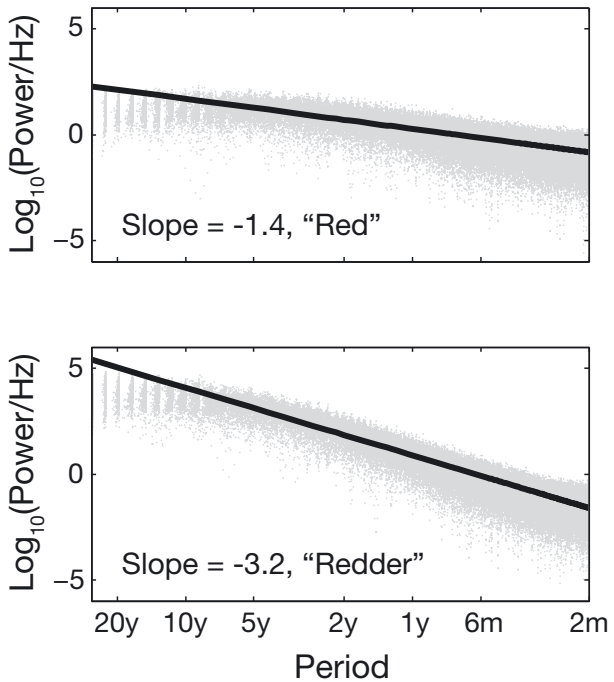

Fig. 1. (a) Simulated white noise time series for 1988-2014 with monthly resolution, (b) integrated once with a characteristic physical timescale for sea surface temperature of $\tau_{\phi}=6$ mo (see Eq. 4). (c) The time series in (b) is integrated again with a characteristic biological timescale of $\tau_{Z}=24$ mo to yield time series (see Eq. 5). Characteristic timescales are taken from Di Lorenzo \& Ohman (2013). Noise time series in left panels are unitless and normalized to have similar dynamic range. Shown on the right are power spectral densities for 1000 randomly generated white noise and subsequent, integrated time series (gray lines), with the average log-log slope plotted in black and noted on each panel 
fica times series are, however, not as red as for $N$. simplex in the double-integration case because there is no initial reddening of power spectra for ocean conditions relative to atmospheric forcing.

Although the single- and double-integration models do not resolve many important physical, biological, and ecological processes, they are appealing in their simplicity and each make a set of testable predictions for population dynamics. In the case of the single integration, phytoplankton should closely track surface ocean conditions that are in turn tied to white noise atmospheric forcing. We would expect atmospheric (e.g. surface winds and heat fluxes), surface ocean (e.g. SST and nutrients), and phytoplankton time series all to have power spectral slopes that are approximately zero (i.e. white noise). The population dynamics of zooplankton should be redder than phytoplankton because of their longer generation lengths. In the case of the double integration, zooplankton dynamics should depend upon changes in ocean surface conditions (e.g. SST), which are in general redder than atmospheric white noise. This leads to power spectral slopes of zooplankton that are even redder than in the single integration case (power spectral slope $<<0$ ). Though Di Lorenzo \& Ohman (2013) did not discuss phytoplankton dynamics in the case of the double-integration model, it seems likely that their dynamics would follow ocean surface conditions. In the case of both models, the power spectral slopes for zooplankton should be redder than for phytoplankton because zooplankton have longer lifespans (i.e. larger $\tau$ ). More generally, for a given characteristic physical timescale $\left(\tau_{\phi}\right)$, increasing the characteristic biological timescale $\left(\tau_{Z}\right)$ should produce more negative power spectral slopes (Eqs. 4 and 5, Fig. S2). However, the generality of the single- and double-integration models to a broad range of species, trophic levels, body sizes, and marine systems remains to be tested.

\section{RESULTS AND DISCUSSION}

\subsection{Power spectral analysis of observations from Station L4}

Power spectral slopes for environmental and plankton time series are presented in Figs. 2 and S3, and compared against each other in Fig. 3. The power spectral slopes of the detrended heat flux and wind stress anomaly times series are 0.12 and -0.066 , respectively (Fig. S3a,b), and are both approximately white noise (power spectral slope $\approx 0$ ). Ocean surface conditions measured at Station L4, here SST and surface nitrate, have power spectral slopes of -0.87 and -1.0 , respectively (Figs. S3c,d), and are relatively red in character. The reddening of SST relative to white noise atmospheric forcing is consistent with the stochastic climate model paradigm (Frankignoul \& Hasselmann 1977, Hall \& Manabe 1997, Deser et al. 2010), where the ocean surface, with its large heat capacity, has a relatively long intrinsic timescale and
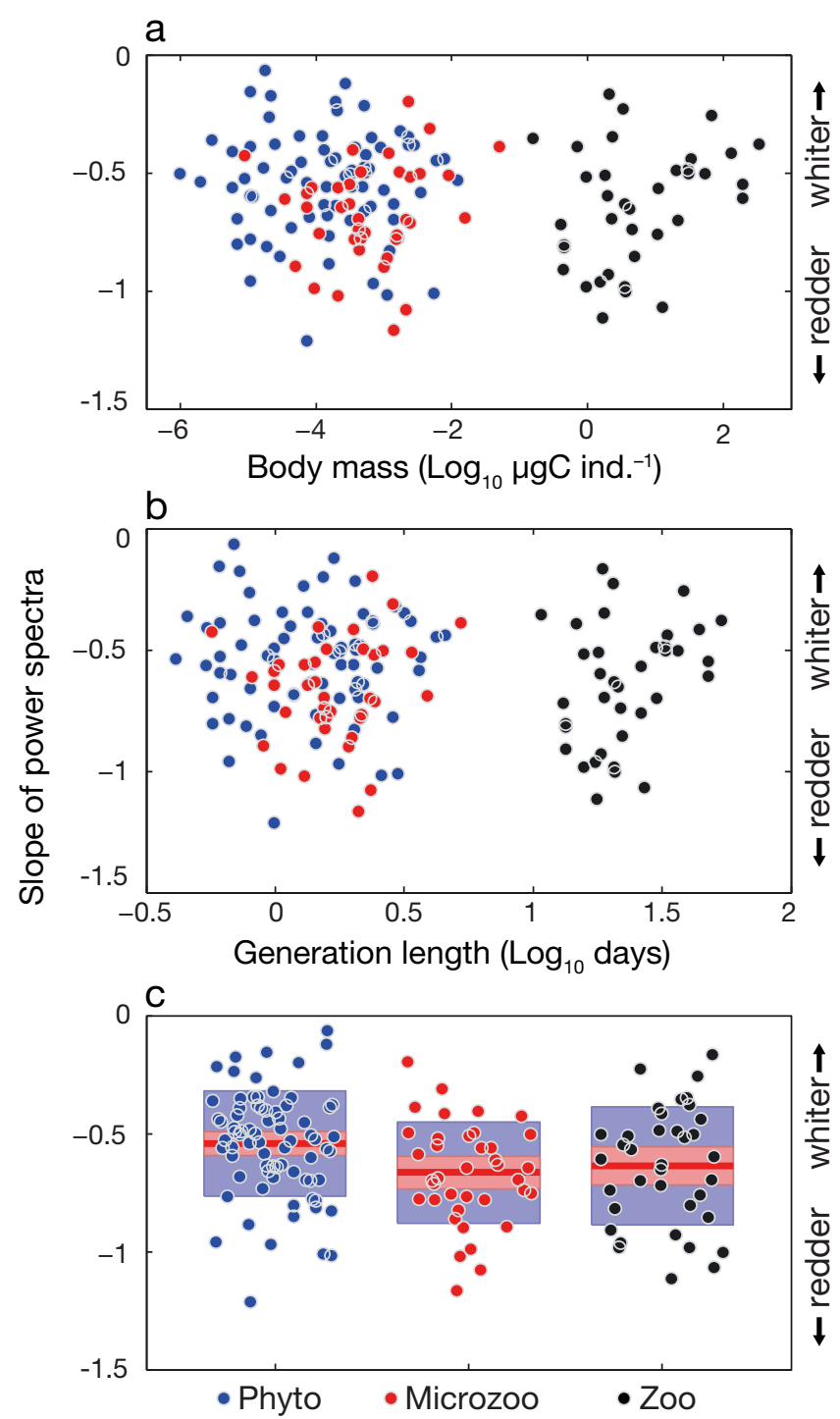

Fig. 2. Power spectral slopes for phytoplankton (blue circles; $\mathrm{n}=75$ ), microzooplankton (red circles; $\mathrm{n}=38$ ), and zooplankton (black circles; $\mathrm{n}=37$ ) taxa observed at Station L4 and calculated from detrended anomaly time series, plotted against estimated $\log _{10}$ of (a) body size and (b) generation length. (c) Mean power spectral slope (heavy red line), \pm 1 $\operatorname{SD}(\sigma$; blue box $)$, and $95 \%$ CIs $( \pm 1.96 \sigma / \sqrt{ } n$; red box $)$ for taxa within each group. Horizontal jittering of individual points in (c) is meaningless but retained to show individual points 
thus integrates atmospheric white noise. The reddening of the surface nitrate power spectra relative to atmospheric variables is consistent with the view that surface nitrate anomalies in this seasonally stratified continental shelf region depend upon vertical mixing driven by wind and buoyancy forcing, either directly or through tidal impacts (Simpson \& Sharples 2012, Williams et al. 2013).

Power spectral slopes for detrended plankton anomaly time series range between a maximum of -0.063 and a minimum of -1.21 , with a mean value of $-0.60 \pm 0.037$ (mean slope $\pm 1.96 \sigma / \sqrt{ } n$ ). Phytoplankton, microzooplankton, and mesozooplankton have mean slopes of $-0.54 \pm 0.050,-0.67 \pm 0.067$, and $-0.64 \pm 0.079$, respectively, averaging over taxa within each group (Fig. 2). These power spectral slopes are red in character, as has been found for other marine and terrestrial taxa (Inchausti \& Halley 2003). There is no significant linear relationship ( $p>$ 0.05 ) between power spectral slope and body size (Fig. 2a) or generation time (Fig. 2b), either across all taxa or within each plankton group. We also examined the relationship between power spectral slope and body size and generation time within just the diatoms, but found no pattern. The average power spectral slopes for microzooplankton and mesozooplankton are significantly lower than for phytoplankton $(2$-sample $t$-test, $\mathrm{p}<0.05)$, while there is no significant difference between slopes for mesozooplankton and microzooplankton ( $\mathrm{p}>0.05$; Fig. 3).

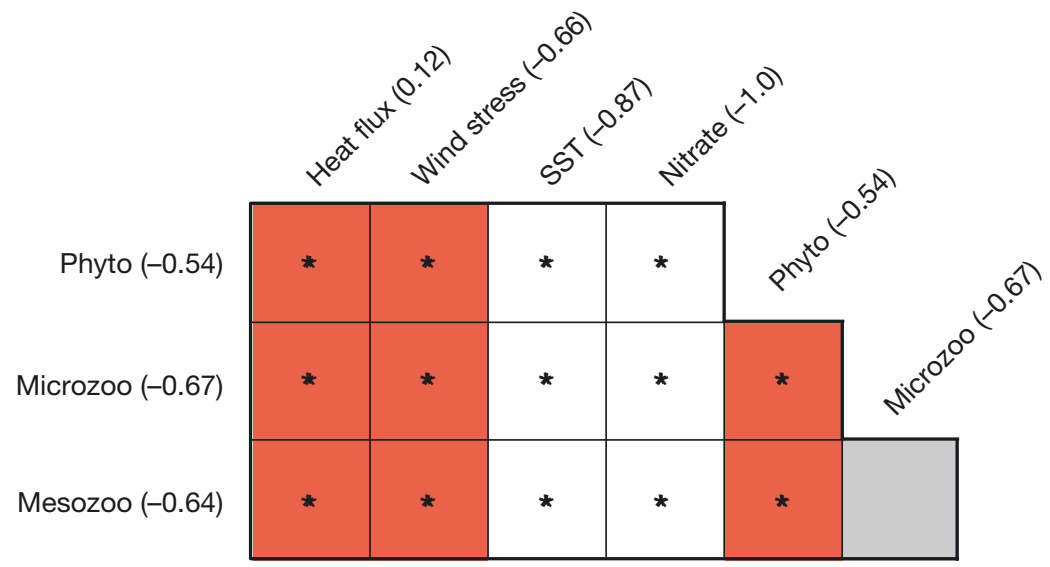

Fig. 3. Phytoplankton, microzooplankton, and mesozooplankton mean power spectral slopes (rows) versus power spectral slopes for environmental variables and other plankton groups (columns). Slopes are indicated in parentheses. Reading across rows, red indicates the mean power spectral slope for the plankton group is redder (more negative) than the variable of comparison by column; white indicates a more positive slope. Differences in mean between plankton groups and environmental variables were tested with 1 -sample $t$ test. Differences in mean between plankton groups were tested with 2-sample $t$-test. Asterisks $(*)$ indicate significant differences in power spectral slopes $(\mathrm{p} \leq$ $0.05)$; gray shading: no significant difference $(p>0.05)$
Phytoplankton, microzooplankton, and mesozooplankton have power spectral slopes that are, on average, redder than heat flux and wind stress but whiter (closer to 0) than SST and nitrate (1-sample $t$ test; $\mathrm{p}<0.05$; Fig. 3).

These findings from Station L4 lend some support to the predictions of the single- and double-integration models (Di Lorenzo \& Ohman 2013). Namely, the power spectral slopes for zooplankton are redder than for phytoplankton, and while the differences are significant, they are small (Figs. 2 \& 3). However, our results from Station L4 contrast with the single- and double-integration models in several ways. The single-integration model proposes that power spectral slopes for ocean surface conditions and phytoplankton should be approximately white noise (slope $\approx 0$ ) and similar to atmospheric forcing, while mesozooplankton should have much redder power spectral slopes. Instead, we found that SST and nitrate power spectral slopes are reddened relative to white noise net heat flux and wind stress, and that both phytoplankton and zooplankton have power spectral slopes that are less red than the ocean surface conditions (Fig. 3).

In the case of a double integration, the conceptual model suggests that ocean surface conditions and phytoplankton should be characterized by redder power spectral slopes than atmospheric white noise forcing, and that mesozooplankton should have slopes that are much redder than their phytoplankton prey (Fig. S2). In agreement with this model, SST and nitrate at Station L4 have redder power spectral slopes than heat flux and wind stress. Yet all plankton groups have power spectral slopes that are whiter - not redder than ocean surface conditions, and the differences in power spectral slope between phytoplankton and zooplankton are quite small. More generally, both the single- and double-integration models suggest that larger bodied, longer lived organisms should have redder power spectra than smaller organisms (Fig. S2), but this does not appear to be generally true of data from Station L4 (Fig. 2).

Overall, observations from Station L4 support the idea that a subtle 'second' ecological integration occurs between phytoplankton prey and zooplankton predators. In several important ways, however, observations do 
not neatly align with the expectations of the singleor double-integration models.

\subsection{Using a plankton model to interpret observations}

To better understand these results, we investigated the dynamics of the idealized plankton community model (Eqs. 1 and 2) when forced by a range of environmental conditions (Eq. 3). In particular, we sought to answer 2 questions arising from the data analyses: Why are the power spectral slopes of zooplankton only slightly redder than for phytoplankton, and why are plankton power spectral slopes generally whiter than ocean surface conditions?

To demonstrate the behavior of the model, we first show the model plankton dynamics for the case where the $K$ time series and spectral characteristics closely resemble nitrate at Station L4 (Fig. 4). Here, the power spectral slope of $K$ is -1.07 (Fig. 4b) and closely matches that of observed nitrate (slope $=-1.0$; Fig. 4a). We consider a single realization of phytoplankton and zooplankton types with the following traits: $r=$ $0.7\left(\mathrm{~d}^{-1}\right), g=0.6\left(\mathrm{~m}^{3}(\mathrm{mmol} \mathrm{N} \mathrm{d})^{-1}\right)$, and $m_{Z}=0.3\left(\mathrm{~m}^{3}(\mathrm{mmol} \mathrm{N} \mathrm{d})^{-1}\right)$. These traits correspond approximately to phytoplankton and zooplankton of 10 and $100 \mu \mathrm{m}$ ESD, respectively, which is on the order of the average 10:1 predator:prey ESD size ratio of marine plankton (Hansen et al. 1994). The size ratio can be much lower for dinoflagellates or much larger for copepods and meroplankton larvae.

Model phytoplankton biomass increases seasonally with $K$, and is closely tracked and ultimately limited by zooplankton feeding (Fig. 4c). Model years with greater $K$ have greater phytoplankton and zooplankton biomass. After removing the climatological seasonal cycle and longterm trend, the power spectral slopes of the monthly anomaly time series for model phytoplankton $(-0.96)$ and zooplankton $(-1.12)$ are similar to $K$ $(-1.07)$. This single instance of the model with a specific combination of $K$ and organism traits suggests that the temporal dynamics of phytoplankton and zooplankton are tightly coupled at these characteristic rates, and that the spectral characteristics of the time series are tied to the spectral nature of $K$.

We conducted 2 further sets of model experiments: (1) to vary $K$ over a plausible range of variation seen in nature, but keep the plankton traits the same and (2) to examine a broad range of potential phytoplankton and zooplankton sizes and associated traits, but keep the $K$ variation the same.

Firstly, we explore model plankton population dynamics when forced by a range of $K$ with power spectral slopes ranging from 0 (white noise) to -1.5 (red noise; Fig. 5). We added noise of a known spectral color to the $K$ seasonal cycle at 10 noise levels between 0 and -1.5 (e.g. $0,-0.15,-0.30, \ldots$ ). At each noise level, we ran 100 replicates and present the ensemble mean power spectral slope and 95\% CIs for phytoplankton and zooplankton (Fig. 5). Plankton traits are kept the same across all model runs, and reflect a $10 \mu \mathrm{m}$ ESD phytoplankton and $100 \mu \mathrm{m}$ ESD zooplankton, as above $\left(r=0.7 \mathrm{~d}^{-1}, g=0.6 \mathrm{~m}^{3}(\mathrm{mmol} \mathrm{N}\right.$ $\mathrm{d})^{-1}$, and $\left.m_{Z}=0.3 \mathrm{~m}^{3}(\mathrm{mmol} \mathrm{N} \mathrm{d})^{-1}\right)$. This prey-
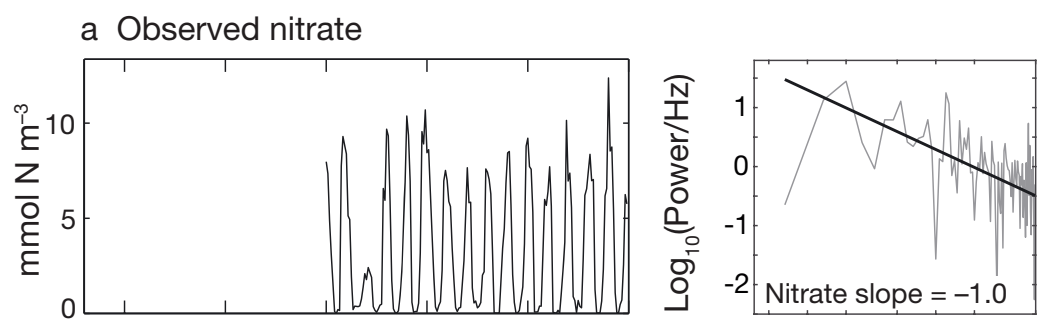

b Synthetic carrying capacity $(K)$
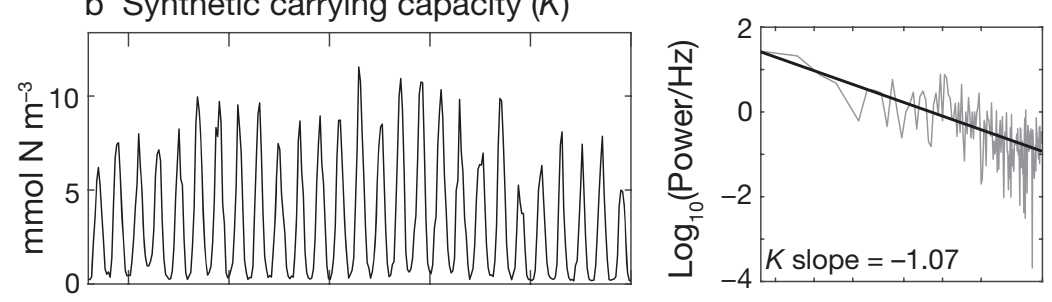

c Simulated $P, Z$
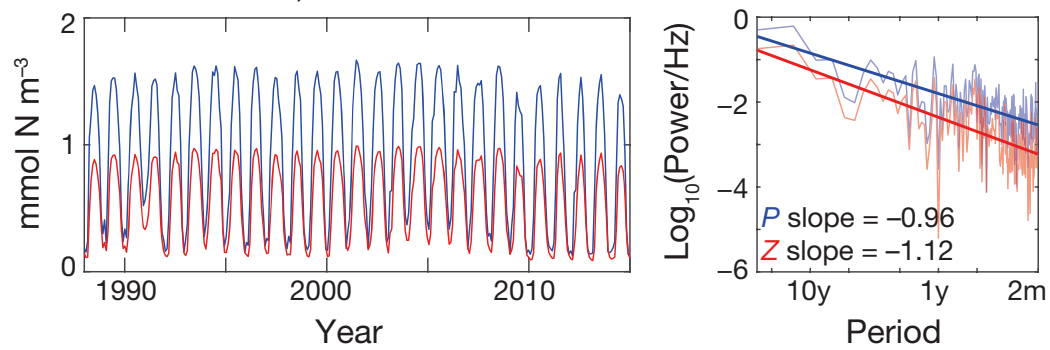

Fig. 4. (a) Observed monthly mean nitrate at Station L4, (b) synthetic carrying capacity $(K)$ resembling the red noise spectra observed in the nitrate time series, and (c) resulting modeled phytoplankton $(P)$ and zooplankton $(Z)$ time series. On the right are the power spectra for time series on the left, after the seasonal cycle and long-term trend were removed 


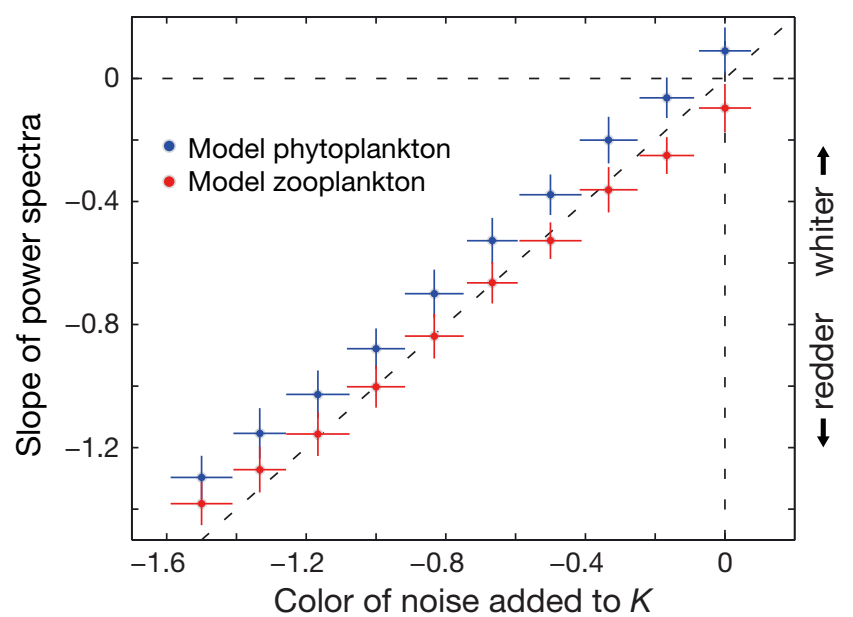

Fig. 5. Average power spectral slopes for model phytoplankton (blue) and zooplankton (red) over a range of synthetic carrying capacity $K$ with noise of a given color, at 10 evenly spaced levels from -1.5 to 0 , added to the repeating seasonal cycle. Dots represent the mean over 100 model iterations over 1988-2014, each with different but spectrally consistent noise added, and the error bars show the 95\% CIs $( \pm 1.96 \sigma / \sqrt{ } n)$. The vertical error bars show the CIs for phytoplankton and zooplankton power spectral slopes, while the horizontal error bars show the CIs for the power spectra slope of $K$. The dashed black diagonal line is the 1:1 line

predator combination is most relevant to an intermediately sized phytoplankton with a microzooplankton predator.

We found that the phytoplankton and zooplankton power spectral slopes nearly matched the power spectral slope of $K$ over a range of environmental conditions plausibly encountered in nature, and that model zooplankton power spectral slopes were slightly redder than for phytoplankton (Fig. 5), in agreement with data from Station L4 (Figs. 2 \& 3). In essence, the plankton are able to nearly track the environmental changes because their generation times are short, on the order of days (Hsieh \& Ohman 2006). The small but noticeable reddening of zooplankton power spectral slopes relative to phytoplankton arises from the longer generation times of model predators compared with prey, and supports the idea that the plankton community itself has some capacity to produce lower frequency variability at Station L4. This reddening, however, is considerably more modest than found by Di Lorenzo \& Ohman (2013) for N. simplex in the California Current, where results indicated that the change in power spectral slope between phytoplankton and zooplankton could be as large as -2 .

Secondly, we explored model plankton population dynamics across a broader range of potential body size and trait combinations of phytoplankton and zoo- plankton, with phytoplankton ranging from 5-200 $\mu \mathrm{m}$ ESD and zooplankton from 50-2000 $\mu \mathrm{m}$ ESD (Fig. 6). For simplicity, we assumed the predator:prey body size ratio is of order 10:1 in ESD, though recognize there is considerable variation around this ratio (Hansen et al. 1994, Atkinson et al. 2014). Model plankton traits $r, g$, and $m_{Z}$ decreased with increasing body size following published allometric relationships (see Section 2.4.1). As was done for Fig. 4, we added noise of power spectral slope of -1.0 to the repeating seasonal cycle of $K$, but conducted 100 replicates for each predator:prey combination. The same $K$ time series were used across different combinations of predator and prey. The goal of these experiments was to estimate the power spectral slope of phytoplankton and zooplankton expected from a particular combination of prey and predator traits experiencing consistent variation in the $K$ of the environment.

For the case of a small phytoplankton (5 $\mu \mathrm{m}$ ESD) grazed upon by a small zooplankton (50 $\mu \mathrm{m}$ ESD; likely microzooplankton), seasonal increases in $K$ are closely tracked by increases in the small phytoplankton and zooplankton (Fig. 6b). The rapid growth of the small, fast growing phytoplankton is grazed down by the relatively efficient microzooplankton-like grazer (Armstrong 1994, Ward et al. 2012). The average power spectral slope over 100 replicates for both phytoplankton and zooplankton is nearly equal to -1 (and approximately equal to the power spectral slope of $K$ ), with phytoplankton being slightly less red (Fig. 6a). For the case of a large phytoplankton (200 $\mu \mathrm{m}$ ESD) grazed upon by a large zooplankton (2000 $\mu \mathrm{m}$ ESD; likely mesozooplankton), there is a temporary decoupling between phytoplankton and zooplankton when $K$ increases (Fig. 6c). Here, grazers are unable to crop phytoplankton population increases, and bloom-like behavior results (Irigoien et al. 2005). In this case, the power spectral slopes of phytoplankton and zooplankton are both whiter than $K$, with phytoplankton being whiter than zooplankton (Fig. 6a).

Thus, the power spectral slopes of plankton become progressively whiter relative to $K$ with increasing body size (moving from left to right in Fig. 6a). The whitening occurs because of noisy bloom dynamics in the model, and may help explain why data from Station L4, a location with a prominent but highly variable plankton bloom in the growing season (Widdicombe et al. 2010b), produce patterns that generally have power spectral slopes that are whiter than ocean surface conditions (Figs. 2, 3, \& S3). Weak integration of noisy blooms by longer lived zooplankton consumers off-sets some, but not all, of the effect. 


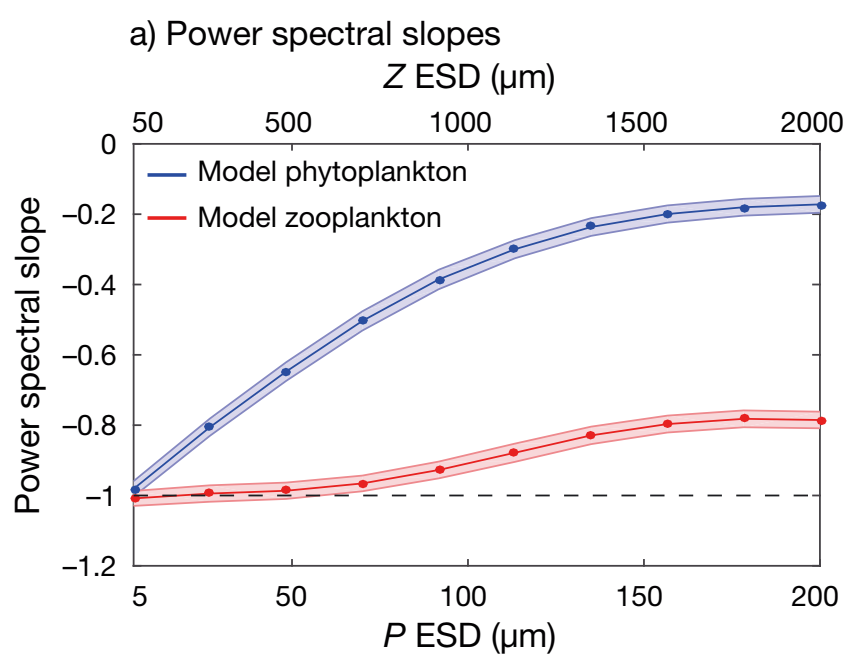

b) $P=5 \mu \mathrm{m}, Z=50 \mu \mathrm{m}$
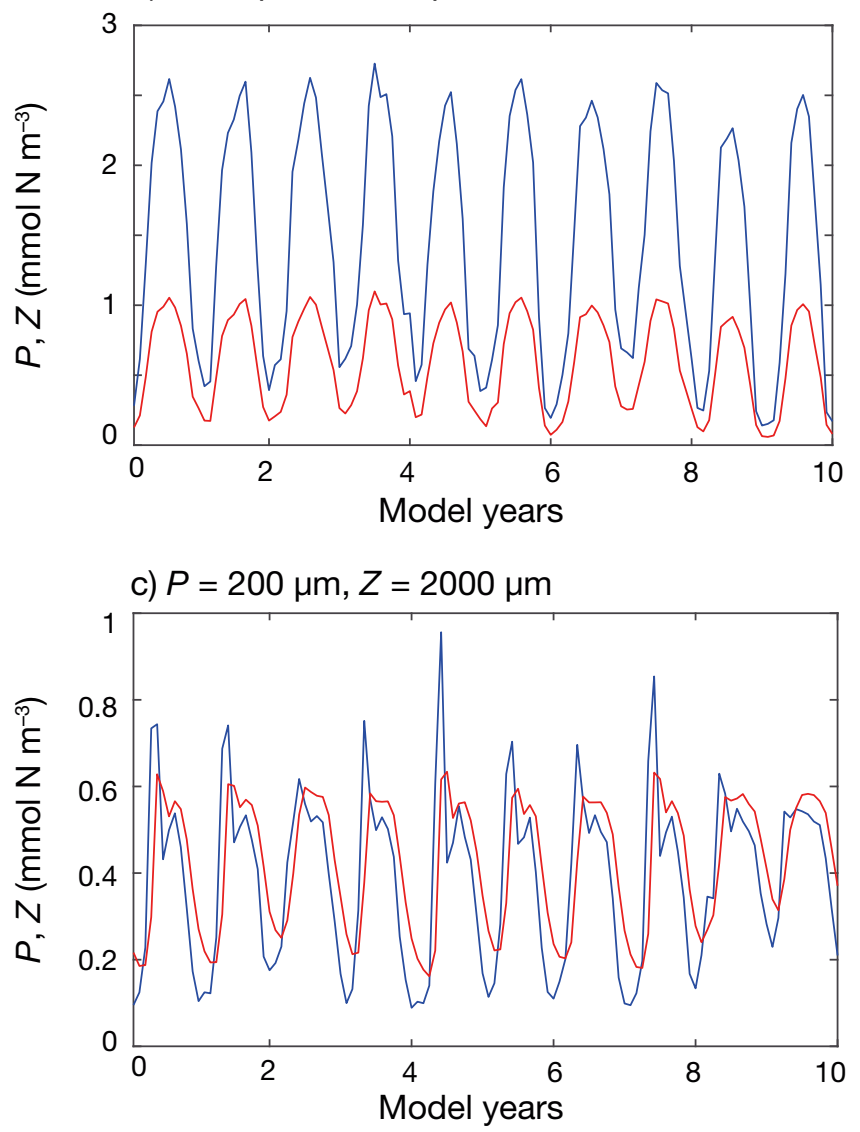

This pattern contrasts with the strong cumulative integration found by Di Lorenzo \& Ohman (2013) in the California Current data.

These overall model results remain robust to changes in the functional response of the consumer (i.e. Type II or Type III instead of the linear Type I response shown here). Because model prey concentrations are typically low compared with half-saturation prey concentrations (Hansen et al. 1997), in Type
Fig. 6. (a) Model power spectral slopes for phytoplankton and zooplankton for a range of possible body size and trait combinations, assuming an average prey:predator equivalent spherical diameter (ESD) body size ratio of 1:10 (Hansen et al. 1994). The power spectral slope of carrying capacity in all cases was set to -1 (horizontal dashed black line). Dots: mean power spectral slope over 100 model iterations for each of 10 predator-prey size combinations; shaded error bars: 95\% CIs $( \pm 1.96 \sigma / \sqrt{ } n)$. Panels (b) and (c) show example time series, taken from model runs in (a), of phytoplankton $(P)$ and zooplankton $(Z)$ dynamics for the case of (b) small phytoplankton (ESD $5 \mu \mathrm{m})$ grazed upon by small zooplankton (ESD $50 \mu \mathrm{m}$ ) and (c) large phytoplankton (ESD $200 \mu \mathrm{m}$ ) grazed upon the large zooplankton (ESD $2000 \mu \mathrm{m}$ ). Only the first $10 \mathrm{yr}$ of each model runs are shown in order to highlight model dynamics

I and Type II formulations, grazing increases approximately linearly with prey concentration. The refuge from grazing at low prey concentrations in the Type III functional response does not change model results as related to population spectral dynamics.

\section{CONCLUSIONS}

We compared the power spectra of atmospheric and oceanographic conditions to the population dynamics of 150 phytoplankton, microzooplankton, and mesozooplankton taxa at Station L4, a well-sampled continental shelf location in the Western English Channel, with the goal of understanding how plankton communities integrate atmospheric and surface ocean variability. Observations from Station L4 indicate that the physical-chemical environment in the ocean surface (SST, nitrate) has redder power spectral slopes than white noise atmospheric forcing (net heat flux, surface wind stress). This reddening from atmosphere to surface ocean is consistent with the stochastic climate model paradigm, where lower frequency variability in the ocean surface layer arises by integrating random variations in the atmosphere (Frankignoul \& Hasselmann 1977, Hall \& Manabe 1997, Deser et al. 2010).

Plankton populations also appear redder than the atmosphere, but are somewhat noisier and whiter compared with ocean surface conditions. Results from a simple trait-based plankton model suggest that the whitening of plankton dynamics relative to environmental forcing is due to seasonal decoupling between prey and predators and resulting noisy bloom dynamics, which can be particularly marked for relatively large phytoplankton and, to a lesser extent, large zooplankton. The observed power spectral slopes of both microzooplankton and mesozoo- 
plankton are slightly redder compared with phytoplankton, but there is considerable overlap between these 3 groups. The model suggests that this slight reddening of zooplankton compared with phytoplankton occurs, in part, because zooplankton predators are generally larger and have consequently longer generation times than their smaller prey. However, we found no statistically significant relationship between body size and power spectral slope in the observations from the Station L4 data. The model results suggest that the color of noise in plankton populations arises from extrinsic environmental forcing but also through filtering of the environmental noise through the food web (see also Xu \& Li 2002, Ripa \& Ives 2003, Vasseur \& Fox 2007).

Our results have several potential implications for understanding how environmental variability impacts marine plankton communities. Firstly, we speculate that the whitening of the plankton time series relative to ocean surface conditions may make it more difficult to definitively link changes in plankton populations or communities to changes in surface ocean forcing (e.g. SST, nitrate). The model indicates this may be particularly true for phytoplankton in regions with strong seasonal bloom dynamics. This finding may help explain why Barton et al. (2015), using Continuous Plankton Recorder data from the North Atlantic, found little correlation between anomalies in diatom abundance, dinoflagellate abundance, and total phytoplankton biomass and SST, stratification, and mixed layer depth anomalies. Note, however, that other studies have argued for a link between SST variability and phytoplankton populations (e.g. Beaugrand et al. 2013, Edwards et al. 2013). In contrast, in this same region and using data from the same survey, zooplankton population anomalies have often been found to have strong statistical relationships with ocean surface conditions (e.g. Fromentin \& Planque 1996, Planque \& Taylor 1998, Greene \& Pershing 2000).

Secondly, our results shed light on the occurrence of regime shifts in marine plankton. Regime shifts, or long-lived and often abrupt transitions from one ecological state to another (Scheffer et al. 2001, Andersen et al. 2009), are a particularly important and poorly understood aspect of low frequency variability (Hare \& Mantua 2000, Beaulieu et al. 2015, Drijfhout et al. 2015). In the single- and double-integration models (Di Lorenzo \& Ohman 2013), zooplankton exhibit considerably more low frequency variability (redder power spectra) than do phytoplankton, and the plankton community itself has the capacity to generate regime-shift-like events, independent of the low frequency variability in the environment. In contrast, data from Station L4 and our idealized model suggest relatively little capacity for spectral decoupling between phytoplankton prey and zooplankton predators with realistic ranges in traits. The implication is that regime shifts in planktonic ecosystems would largely be driven by low frequency variability in other components of the Earth System; for example, by changes in modes of climate variability (e.g. Hare \& Mantua 2000, Edwards et al. 2013, Beaugrand et al. 2019) or sea ice melting (Grebmeier et al. 2006, Arrigo et al. 2008).

Overall, plankton and environmental data from Station L4 did not neatly conform either to the singleor the double-integration models proposed by $\mathrm{Di}$ Lorenzo \& Ohman (2013) for long-lived krill (1-2 yr) in the California Current Ecosystem. The California Current region is an upwelling system with strong decadal changes in geostrophic transport (Bograd et al. 2001), whereas Station L4 is a dynamic inshore, albeit seasonally stratified continental shelf ecosystem (Atkinson et al. 2018). It is therefore not surprising that these systems, with strongly contrasting physical dynamics and plankton communities, would have different pathways linking atmospheric and ecological variability. Moreover, our study investigated 150 plankton taxa, up to and including krill and some fish larvae, with estimated generation lengths ranging from less than a day to a few months. It is possible that the integration effects noted by $\mathrm{Di}$ Lorenzo \& Ohman (2013) may be present only for larger, longer lived zooplankton (like $N$. simplex), higher trophic levels, or taxa not covered by our analysis. For example, larger species with multi-year life cycles such as fish and some of the krill species can have fundamentally different reproductive strategies compared to species with cycles of $1 \mathrm{yr}$ or less. Multi-year life cycles can thus lead to only a few successful spawnings per decade and thus to great inter-annual variability in population size and strong decadal-scale variability linked to climatic drivers (Atkinson et al. 2014). Conversely, diverse assemblages of smaller inshore plankton at Station L4 have strong predation controls constraining population sizes of key grazers (Maud et al. 2015) and reproductive strategies that are robust to variation in the quantity and timing of food (Atkinson et al. 2015).

We suggest that the work started by Di Lorenzo \& Ohman (2013), and extended here in this study for Station L4, should be complemented by a globalscale meta-analysis of plankton time series covering a broad range of ecosystems and organisms, with a goal of identifying common spectral patterns and 
mechanisms linking variability in the atmosphere, ocean, and plankton communities (for example, Mackas \& Beaugrand 2010, Batchelder et al. 2012, Mackas et al. 2012).

Acknowledgements. We thank the Plymouth Marine Laboratory for the provision of data from the Western Channel Observatory's L4 time series, which is funded by the UK's Natural Environmental Research Council's National Capability Programme. Up-to-date versions of Station L4 data are available from the British Oceanographic Data Centre (www. bodc.ac.uk). National Centers for Environmental Prediction reanalysis data were provided by NOAA's Physical Sciences Division (www.esrl.noaa.gov/psd/). We also thank NASA Ocean Biology Processing Group for the production, availability and maintenance of the remote sensing PAR data analyzed in this work (https://oceancolor.gsfc.nasa.gov). A.D.B., F.G.T., and C.A.S. acknowledge support from NOAA. A.D.B. acknowledges support from the Simons Foundation. F.G.T. acknowledges support from The Nippon FoundationUBC Nereus Program. A.A. and C.E.W. acknowledge support from the Natural Environment Research Council through its Long-term Single Centre Science Programme, 'Climate Linked Atlantic Sector Science' (NE/R015953/1).

\section{LITERATURE CITED}

Acuña JL, Lopez-Urrutia A, Colin S (2011) Faking giants: the evolution of high prey clearance rates in jellyfishes. Science 333:1627-1629

Andersen T, Carstensen J, Hernandez-Garcia E, Duarte CM (2009) Ecological thresholds and regime shifts: approaches to identification. Trends Ecol Evol 24:49-57

Anderson CN, Hsieh CH, Sandin SA, Hewitt R and others (2008) Why fishing magnifies fluctuations in fish abundance. Nature 452:835-839

Armstrong RA (1994) Grazing limitation and nutrient limitation in marine ecosystems - steady-state solutions of an ecosystem model with multiple food-chains. Limnol Oceanogr 39:597-608

Arrigo KR, van Dijken G, Pabi S (2008) Impact of a shrinking Arctic ice cover on marine primary production. Geophys Res Lett 35:L19603

Atkinson A, Hill SL, Barange M, Pakhomov EA and others (2014) Sardine cycles, krill declines, and locust plagues: revisiting 'wasp-waist' food webs. Trends Ecol Evol 29: 309-316

Atkinson A, Harmer RA, Widdicombe CE, McEvoy AJ and others (2015) Questioning the role of phenology shifts and trophic mismatching in a planktonic food web. Prog Oceanogr 137:498-512

*Atkinson A, Polimene L, Fileman ES, Widdicombe CE and others (2018) Comment. What drives plankton seasonality in a stratifying shelf sea? Some competing and complementary theories. Limnol Oceanogr 63:2877-2884

Atkinson A, McEvoy AJ, Lilley M (2019) Plymouth L4 time series (1988-2017) of zooplankton abundance, biomass, and traits. British Oceanographic Data Centre, Plymouth

Barton AD, Lozier MS, Williams RG (2015) Physical controls of variability in North Atlantic phytoplankton communities. Limnol Oceanogr 60:181-197

Barton AD, Irwin AJ, Finkel ZV, Stock CA (2016) Anthro- pogenic climate change drives shift and shuffle in North Atlantic phytoplankton communities. Proc Natl Acad Sci USA 113:2964-2969

Batchelder HP, Mackas DL, O'Brien TD (2012) Spatialtemporal scales of synchrony in marine zooplankton biomass and abundance patterns: a world-wide comparison. Prog Oceanogr 97-100:15-30

*Beaugrand G, McQuatters-Gollop A, Edwards M, Goberville E (2013) Long-term responses of North Atlantic calcifying plankton to climate change. Nat Clim Chang 3:263-267

* Beaugrand G, Conversi A, Atkinson A, Cloern J and others (2019) Prediction of unprecedented biological shifts in the global ocean. Nat Clim Chang 9:237-243

* Beaulieu C, Cole H, Henson S, Yool A and others (2015) Marine regime shifts in ocean biogeochemical models: a case study in the Gulf of Alaska. Biogeosciences Discuss 12:14003-14048

* Behrenfeld MJ, O'Malley RT, Siegel DA, McClain CR and others (2006) Climate-driven trends in contemporary ocean productivity. Nature 444:752-755

* Benincà E, Dakos V, Van Nes EH, Huisman J, Scheffer M (2011) Resonance of plankton communities with temperature fluctuations. Am Nat 178:E85-E95

* Bissinger JE, Montagnes DJ, Sharples J, Atkinson D (2008) Predicting marine phytoplankton maximum growth rates from temperature: improving on the Eppley curve using quantile regression. Limnol Oceanogr 53:487-493

* Bograd SJ, Chereskin TK, Roemmich D (2001) Transport of mass, heat, salt, and nutrients in the southern California Current System: annual cycle and interannual variability. J Geophys Res Oceans 106:9255-9275

* Bopp L, Resplandy L, Orr JC, Doney SC and others (2013) Multiple stressors of ocean ecosystems in the $21^{\text {st }}$ century: projections with CMIP5 models. Biogeosciences 10: 6225-6245

* Deser C, Alexander MA, Xie SP, Phillips AS (2010) Sea surface temperature variability: patterns and mechanisms. Annu Rev Mar Sci 2:115-143

*Di Lorenzo E, Ohman MD (2013) A double-integration hypothesis to explain ocean ecosystem response to climate forcing. Proc Natl Acad Sci USA 110:2496-2499

* Drijfhout S, Bathiany S, Beaulieu C, Brovkin V and others (2015) Catalogue of abrupt shifts in Intergovernmental Panel on Climate Change climate models. Proc Natl Acad Sci USA 112:E5777-E5786

Dutkiewicz S, Morris JJ, Follows MJ, Scott JR, Levitan O, Dyhrman ST, Berman-Frank I (2015) Impact of ocean acidification on the structure of future phytoplankton communities. Nat Clim Change 5:1002-1006

Edwards M, Richardson AJ (2004) Impact of climate change on marine pelagic phenology and trophic mismatch. Nature 430:881-884

Edwards KF, Thomas MK, Klausmeier CA, Litchman E (2012) Allometric scaling and taxonomic variation in nutrient utilization traits and maximum growth rate of phytoplankton. Limnol Oceanogr 57:554-566

* Edwards M, Beaugrand G, Helaouët P, Alheit J, Coombs S (2013) Marine ecosystem response to the Atlantic Multidecadal Oscillation. PLOS ONE 8:e57212

* Eloire D, Somerfield PJ, Conway DVP, Halsband-Lenk C, Harris R, Bonnet D (2010) Temporal variability and community composition of zooplankton at Station L4 in the Western Channel: 20 years of sampling. J Plankton Res 32:657-679 
Eppley RW (1972) Temperature and phytoplankton growth in the sea. Fish Bull 70:1063-1085

Ferguson JM, Carvalho F, Murillo-Garcia O, Taper ML, Ponciano JM (2016) An updated perspective on the role of environmental autocorrelation in animal populations. Theor Ecol 9:129-148

Frankignoul C, Hasselmann K (1977) Stochastic climate models, Part II: application to sea-surface temperature anomalies and thermocline variability. Tellus 29:289-305

Fromentin JM, Planque B (1996) Calanus and environment in the eastern North Atlantic. II. Influence of the North Atlantic Oscillation on C. finmarchicus and C. helgolandicus. Mar Ecol Prog Ser 134:111-118

* García-Carreras B, Reuman DC (2011) An empirical link between the spectral colour of climate and the spectral colour of field populations in the context of climate change. J Anim Ecol 80:1042-1048

Gause GF, Smaragdova NP, Witt AA (1936) Further studies of interaction between predators and prey. J Anim Ecol 5:1-18

Gillooly JF (2000) Effect of body size and temperature on generation time in zooplankton. J Plankton Res 22: 241-251

* Grebmeier JM, Overland JE, Moore SE, Farley EV and others (2006) A major ecosystem shift in the northern Bering Sea. Science 311:1461-1464

* Greene CH, Pershing AJ (2000) The response of Calanus finmarchicus populations to climate variability in the Northwest Atlantic: basin-scale forcing associated with the North Atlantic Oscillation. ICES J Mar Sci 57: 1536-1544

Hall A, Manabe S (1997) Can local linear stochastic theory explain sea surface temperature and salinity variability? Clim Dyn 13:167-180

* Hansen B, Bjørnsen PK, Hansen PJ (1994) The size ration between planktonic predators and their prey. Limnol Oceanogr 39:395-403

*Hansen B, Bjørnsen BW, Hansen PJ (1997) Zooplankton grazing and growth: scaling within the $2-2000 \mu \mathrm{m}$ body size range. Limnol Oceanogr 42:687-704

Hare SR, Mantua NJ (2000) Empirical evidence for North Pacific regime shifts in 1977 and 1989. Prog Oceanogr 47:103-145

*Henson S, Lampitt R, Johns D (2012) Variability in phytoplankton community structure in response to the North Atlantic Oscillation and implications for organic carbon flux. Limnol Oceanogr 57:1591-1601

Hirst AG, Bunker AJ (2003) Growth of marine planktonic copepods: global rates and patterns in relation to chlorophyll $a$, temperature, and body weight. Limnol Oceanogr 48:1988-2010

Hsieh CH, Ohman MD (2006) Biological responses to environmental forcing: the linear tracking window hypothesis. Ecology 87:1932-1938

*Hsieh CH, Glaser SM, Lucas AJ, Sugihara G (2005) Distinguishing random environmental fluctuations from ecological catastrophes for the North Pacific Ocean. Nature 435:336-340

Hunter-Cevera KR, Neubert MG, Solow AR, Olson RJ, Shalapyonok A, Sosik HM (2014) Diel size distributions reveal seasonal growth dynamics of a coastal phytoplankter. Proc Natl Acad Sci USA 111:9852-9857

Inchausti P, Halley J (2001) Investigating long-term ecological variability using the global population dynamics database. Science 293:655-657
Inchausti P, Halley J (2003) On the relation between temporal variability and persistence time in animal populations. J Anim Ecol 72:899-908

Irigoien X, Flynn KJ, Harris RP (2005) Phytoplankton blooms: A 'loophole' in microzooplankton grazing impact? J Plankton Res 27:313-321

Ives AR, Abbott KC, Ziebarth NL (2010) Analysis of ecological time series with $\operatorname{ARMA}(p, q)$ models. Ecology 91: 858-871

Kalnay E, Kanamitsu M, Kistler R, Collins W and others (1996) The NCEP/NCAR 40-year reanalysis project. Bull Am Meteorol Soc 77:437-471

Kovala PE, Larrance JP (1966) Computation of phytoplankton cell numbers, cell volume, cell surface area and plasma volume per litre, from microscopical counts. Special Report, Vol 38. University of Washington, Seattle, WA

Lampert W (1989) The adaptive significance of diel migration of zooplankton. Funct Ecol 3:21-27

* Mackas DL, Beaugrand G (2010) Comparisons of zooplankton time series. J Mar Syst 79:286-304

Mackas DL, Pepin P, Verheye H (2012) Interannual variability of marine zooplankton and their environments: within- and between-region comparisons. Prog Oceanogr 97-100:1-14

Margalef R (1978) Life-forms of phytoplankton as survival alternatives in an unstable environment. Oceanol Acta 1: 493-509

Maud JL, Atkinson A, Hirst AG, Lindeque PK and others (2015) How does Calanus helgolandicus maintain its population in a variable environment? Analysis of a 25-year time series from the English Channel. Prog Oceanogr 137:513-523

McEvoy AJ, Harmer RA, Halsband-Lenk C (2012) Time series of zooplankton abundance at Station L4 in the English Channel from 1988 to 2011. Pangaea data set, doi:10.1594/ PANGAEA.778092

McGurk MD (1986) Natural mortality of marine pelagic fish eggs and larvae: role of spatial patchiness. Mar Ecol Prog Ser 34:227-242

*Menden-Deuer S, Lessard EJ (2000) Carbon to volume relationships for dinoflagellates, diatoms, and other protist plankton. Limnol Oceanogr 45:569-579

*Montagnes DJS, Fenton A (2012) Prey-abundance affects zooplankton assimilation efficiency and the outcome of biogeochemical models. Ecol Modell 243:1-7

*Moore CM, Mills MM, Arrigo KR, Berman-Frank I and others (2013) Processes and patterns of oceanic nutrient limitation. Nat Geosci 6:701-710

NASA OBPG (National Aeronautics and Space Administration Ocean Biology Processing Group) (2017) Moderateresolution imaging spectroradiometer (MODIS) aqua photosynthetically available radiation data; 2014 reprocessing. NASA Ocean Biology Distributed Active Archive Center, Goddard Space Flight Center, Greenbelt, MD

Nicholson AJ (1957) The self-adjustment of populations to change. Cold Spring Harb Symp Quant Biol 22: 153-173

\% Ohman MD, Hirche HJ (2001) Density-dependent mortality in an oceanic copepod population. Nature 412:638-641

* Overland JE, Percival DB, Mofjeld HO (2006) Regime shifts and red noise in the North Pacific. Deep Sea Res I 53: $582-588$

* Planque B, Taylor AH (1998) Long-term changes in zooplankton and the climate of the North Atlantic. ICES J Mar Sci 55:644-654 
Platt T, Denman KL (1975) Spectral analysis in ecology. Annu Rev Ecol Syst 6:189-210

Ripa J, Ives AR (2003) Food web dynamics in correlated and autocorrelated environments. Theor Popul Biol 64:369-384

Roughgarden J (1988) Recruitment dynamics in complex life cycles. Science 241:1460-1466

Royama T (1981) Fundamental concepts and methodology for the analysis of animal population dynamics, with particular reference to univoltine species. Ecol Monogr 51: 473-493

Rudnick DL, Davis RE (2003) Red noise and regime shifts. Deep Sea Res I 50:691-699

Ruokolainen L, Ripa J (2012) The strength of species interactions modifies population responses to environmental variation in competitive communities. J Theor Biol 310: 199-205

Ruokolainen L, Linden A, Kaitala V, Fowler MS (2009) Ecological and evolutionary dynamics under coloured environmental variation. Trends Ecol Evol 24:555-563

Scheffer M, Rinaldi S, Kuznetsov YA, van Nes EH (1997) Seasonal dynamics of Daphnia and algae explained as a periodically forced predator-prey system. Oikos 80: 519-532

Scheffer M, Carpenter S, Foley JA, Folke C, Walker B (2001) Catastrophic shifts in ecosystems. Nature 413: 591-596

Simpson JH, Sharples J (2012) Introduction to the physical and biological oceanography of shelf seas. Cambridge University Press, Cambridge

Smyth TJ, Fishwick JR, Al-Moosawi L, Cummings DG and others (2010) A broad spatio-temporal view of the Western English Channel observatory. J Plankton Res 32: 585-601

Smyth TJ, Hardman-Mountford N, Frost M, Fishwick JR (2011) Temperature and salinity from time series Station L4 in the western English Channel from 1988 to 2011. Pangaea data set, doi:10.1594/PANGAEA.757204

Steele JA (1985) A comparison of terrestrial and marine ecological systems. Nature 313:355-358

Stock CA, Dunne JP, John JG (2014) Global-scale carbon and energy flows through the marine planktonic food web: an analysis with a coupled physical-biological model. Prog Oceanogr 120:1-28

Straile D (1997) Gross growth efficiencies of protozoan and metazoan zooplankton and their dependence on food

Editorial responsibility: Alejandro Gallego,

Aberdeen, UK concentration, predator-prey weight ratio, and taxonomic group. Limnol Oceanogr 42:1375-1385

Theil H (1950) A rank-invariant method of linear and polynomial regression analysis, iii. Proc R Neth Acad Sci 53: $1397-1412$

Timmer J, König M (1995) On generating power law noise. Astron Astrophys 300:707-710

Utermöhl H (1958) Zur Vervollkommnung der quantitativen Phytoplankton-Methodik. Mitt Int Ver Theor Angew Limnol 9:1-38

Vasseur DA (2007) Populations embedded in trophic communities respond differently to coloured environmental noise. Theor Popul Biol 72:186-196

Vasseur DA, Fox JW (2007) Environmental fluctuations can stabilize food web dynamics by increasing synchrony. Ecol Lett 10:1066-1074

Vasseur DA, Yodzis P (2004) The color of environmental noise. Ecology 85:1146-1152

WWard BA, Dutkiewicz S, Jahn O, Follows MJ (2012) A sizestructured food-web model for the global ocean. Limnol Oceanogr 57:1877-1891

* Widdicombe C, Eloire D, Harbour D, Harris RP, Somerfield PJ (2010a) Time series of phyto- and microzooplankton abundance and composition at Station L4 in the English Channel from 1988 to 2009. Pangaea data set, doi: 10.1594/PANGAEA.758061

Widdicombe CE, Eloire D, Harbour D, Harris RP, Somerfield PJ (2010b) Long-term phytoplankton community dynamics in the Western English Channel. J Plankton Res 32: 643-655

Williams C, Sharples J, Mahaffey C, Rippeth T (2013) Winddriven nutrient pulses to the subsurface chlorophyll maximum in seasonally stratified shelf seas. Geophys Res Lett 40:5467-5472

Woodward EMS, Rees AP (2001) Nutrient distributions in an anticyclonic eddy in the northeast Atlantic Ocean, with reference to nanomolar concentrations. Deep Sea Res II 48:775-793

WWoodward EM, Harris C, Al-Moosawi L (2011) Nutrient concentration profiles from time series stations E1 and L4 in the western English Channel from 2000 to 2010. Pangaea data set, doi:10.1594/PANGAEA.771808

Xu CL, Li ZZ (2002) Population's response to environmental noise: the influence of food web structure. Ecol Modell 154:193-202

Submitted: October 28, 2019; Accepted: July 17, 2020

Proofs received from author(s): August 11, 2020 